Indonesian Journal of Medicine (2018), 3(3): 134-138

https://doi.org/10.26911/theijmed.2018.03.03.02

\title{
Functional Knee Score in Knee Osteoarthritis with Tibial Defect Performed Total Knee Arthroplasty with Screw Augmentation
}

\author{
Fajar Baskoro Gardjito, Arief Indra Perdana, \\ Ismail Mariyanto, Mujaddid Idulhaq, Pamudji Utomo
}

Department of Orthopaedic and Traumatology, Faculty of Medicine, Universitas Sebelas Maret/
Dr. Moewardi Hospital/Prof. Dr. R. Soeharso Orthopaedic Hospital

\begin{abstract}
Background: Long-standing knee osteoarthritis also is a common cause of severe bone deficiency (especially proximal tibia). Total knee arthroplasty is indicated in patient with knee osteoarthritis who did not able to perform activity daily living. This study aimed to evaluate the functional knee score of the patient with knee osteoarthritis who performed total knee arthroplasty with screw augmentation.

Subjects and Method: This was an analytic observational study conducted at Soeharso Orthopaedic Hospital, Surakarta, Central Java, from January to December 2016. A sample of 30 patients with knee osteoarthritis with tibial defect who performed total knee arthroplasty with screw augmentation was selected for this study. The dependent variable was functional knee score. The independent variable was knee arthroplasty with screw augmentation. Knee function was measured by knee society score. The difference of knee function score between before and after total knee arthroplasty with screw augmentation was analyzed by t test.

Results: There were 30 patients (25 females and 5 males) with age between 54 to 73 years old. Mean of knee society score post operative (mean $=82.7 ; \mathrm{SD}=6.29$ ) was higher than pre operative (mean $=30.5 ; \mathrm{SD}=6.74)$ and it was statistically significant $(\mathrm{p}=0.001)$.

Conclusion: Knee society score after total knee arthroplasty with screw augmentation is higher than before surgery.
\end{abstract}

Keywords: functional knee score, osteoarthritis, screw augmentation

\section{Correspondence:}

Fajar Baskoro Gardjito, Department of Orthopaedic and Traumatology, Faculty of Medicine, Universitas Sebelas Maret/Dr. Moewardi Hospital/Prof. Dr. R. Soeharso Orthopaedic Hospital. Email: baskovic9237@gmail.com.

\section{BACKGROUND}

$\overline{\text { Osteoarthritis of the knee have been one of }}$ diseases that may cause pain and disability that interfere activity daily living of person. According to World Health Organization in 2004, Osteoarthritis of the knee have been suffered by more than 151 million in population in the world, and more than 24 million in population in Southeast Asia. Osteoarthritis of the knee is chronic disease that not only interfere the person's activity daily living, but also may effect in economic, psychologic and social, not only the person who suffer osteoarthritis of the knee, buat also their family and environment (Abdeen, Collen, and Vince, 2010).

There is still no exact treatment may cure the osteoarthritis the knee. The recent non-operative treatment now is focused on relieving pain, and maintaining the function of the knee joint that develop osteoarthritis. The treatment include physical exercise, prevent excessive body-weight, and pharmacological agent (Kouk et al., 2018; Rajesh, 2012). 
Operative treatment indicated if there is no improvement after non-operative treatment, or in patient with disabling pain that limit activity daily living, or in patient with severe deformity due to osteoarthritis of the knee. Surgery procedure include osteophyte removal (debridement), realignment osteotomy, arthroplasty (Unicompartmental Arthroplasty or Total Knee Arthroplasty), or Arthrodesis (Fusion of the knee joint). In the patient with longstanding cases of osteoarthritis of the knee, the deformity may be associated with bone deficiency, i.e. defect at the proximal tibia (medial plateau defect in Osteoarthritis knee with varus deformity). There are several methods to treat these condition, include cement-filling, impacted cancellous bone graft, structural bone grafts, metal augmentation, screw augmentation (screw is fixed within cement to augment the tibial defect). One of those technique, i.e screw augmentation, in some studies shown that no failure and no radiolucency progression of tibia, in 25 kness that performed Total Knee Arthroplasty in 7 years follow-up, and in 145 knee performed Total Knee Arthroplasty, failure (collapase) occur in 3 knee, but no need further revision (Bilgen, Eken, \& Guney, 2017).

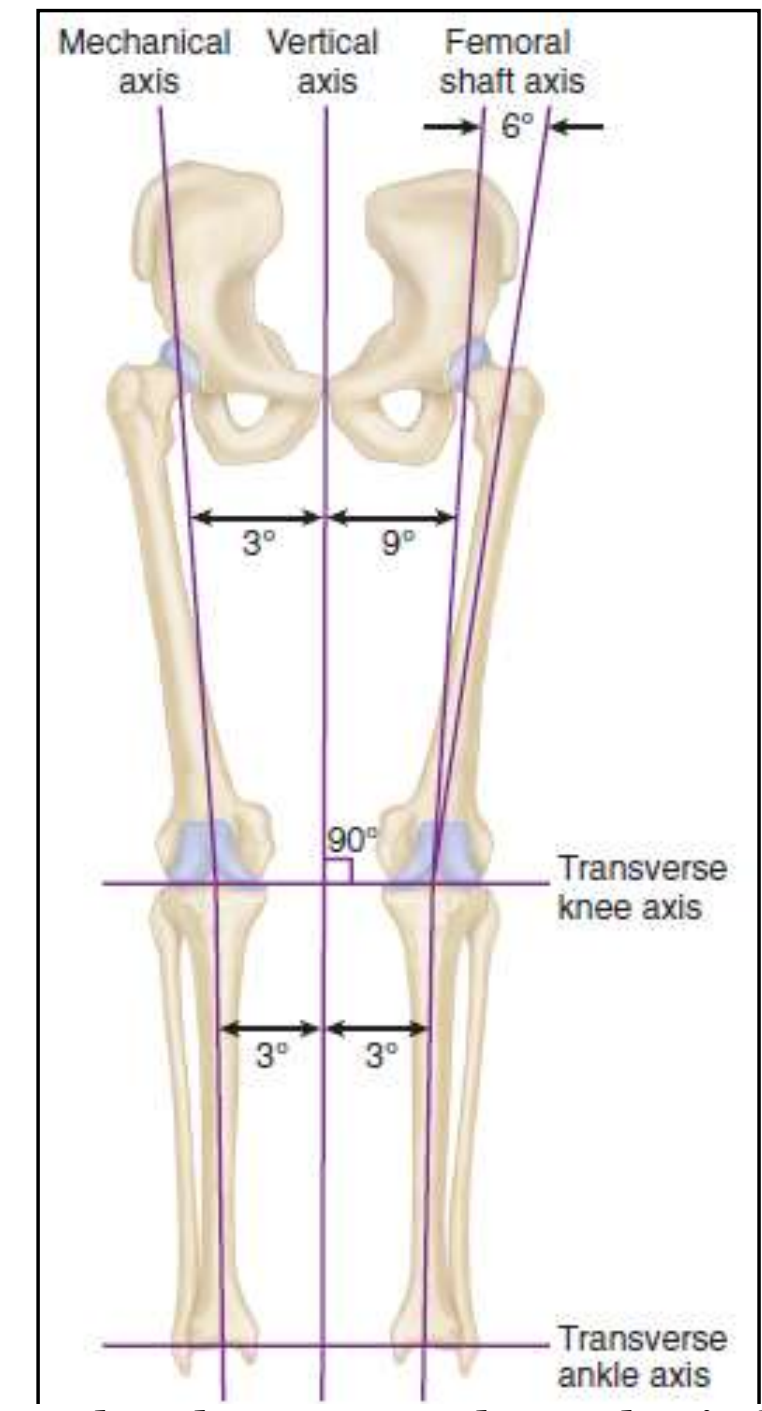

Figure1. Total knee arthroplasty restore the mechanical axis of knee osteoarthritic, that correlated with optimal long-term outcome (Rajesh, 2012) 
Bone deficiencies management (especially defect in the proximal tibial articular surface) in long-standing cases of osteoarthritis of the knee that requiring total knee arthroplasty, depend on the extent of the defect. Defect that occur due to articular surface destruction, may lead to severe deformity in patient with osteoarthritis of the knee.

The management of those bone deficiencies have a purpose for :

- Implant stabilizing

- Implant supporting

- Implant durability

From the configuration, the defect can be divided into contained (defect within intact cortical rim) and non-contained (no intact cortical rim).

Rand classified the proximal tibia defect into:(Rajesh, 2012)

Type I: focal metaphyseal defect, intact cortical rim

Type II: extensive metaphyseal defect, intact cortical rim

Type III: combined metaphyseal and cortical defect

Rajesh (2012), Scott (2012), Canales (2017) stated that treatment for the tibial defect depends on two factors:

- The defect, whether contained or noncontained

- Size of the defect

\section{- Contained Defect}

- Small $(<5 \mathrm{~mm})$ - cement or bonegraft / cement with screw (screw augmentation)

- Large (>5 mm) - autologous or allogenousbonegraft

\section{- Uncontained Defect}

- Small $(<5 \mathrm{~mm})$ - cement only or screw augmentation

- Intermediate (5-10 mm) - modular wedges

Large $(>10 \mathrm{~mm}) \quad-$ structural allograft or modular augmentation
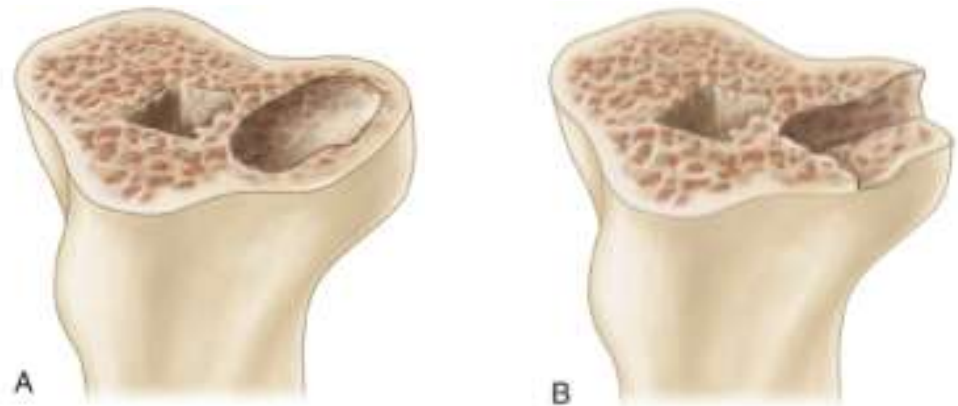

Figure2. (A) Contained; (B) Non-contained(Rajesh, 2012)
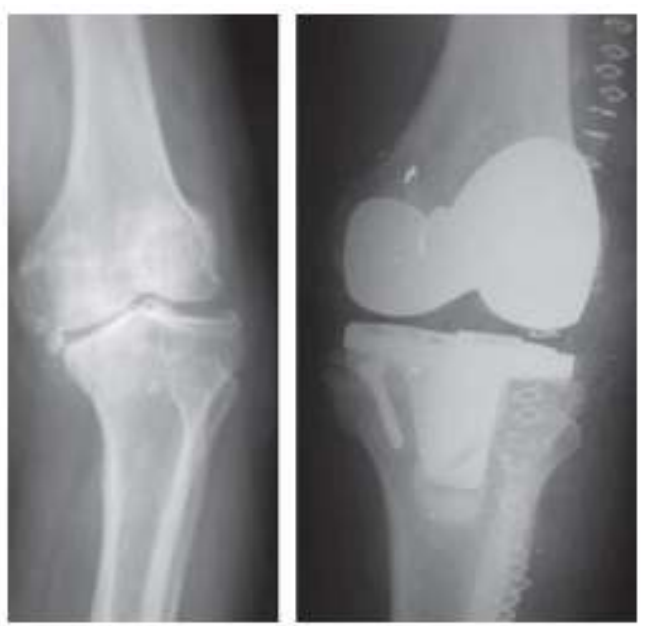

Picture 3. Screw augmentation in patient with knee osteoarthritis with tibial defect(Rajesh, 2012) 
Gardjito et al./ Functional Knee Score in Knee Osteoarthritis

\section{SUBJECTS AND METHOD}

\section{Study Design}

This was an analytic observational study with a cross-sectional design. The study was carried out in Prof. Soeharso Orthopaedic Hospital, Surakarta, Central Java.

\section{Population and Sample}

The study population was all knee osteoarthritis patients with tibial defect that had been underwent total knee arthroplasty with screw augmentation, with 3 months minimal follow-up after operation. A sample of 30 patients were selec The sample was taken with total sampling, with population from Outpatient Clinic of Soeharso Orthopaedic Hospital. There are 30 total samples.

\section{Study Variables}

Patient data who met the inclusion criteria was taken from medical record of Outpatient Clinic of SoeharsoOrthopaedic Hospital. The patients evaluated using Knee Society Score. The dependent variable wasknee society score postoperative. The independent variables were gender and age.

\section{Data Analysis}

Correlation between gender, age, and postoperative knee society score were analyzed by multiple linear regression. Difference between before and after treatment was analyzed by $t$ test.

\section{Research Ethics}

Research ethics in this study was obtained from Research Ethics Committee with number DL.02.01/XXX.2/3881/2018.

\section{RESULTS}

\section{Sample characteristics}

As many as 30 patients with knee osteoarthritis who performed total knee arthroplasty with screw augmentation were at age 54 to 73 years old, 25 females and 5 males.

\section{Bivariate analysis}

Table 1 showed the results of $t$ test of knee society score between pre and post operative. Table 1 showed that mean of knee society score post operative (mean $=82.7$; $\mathrm{SD}=6.29$ ) was higher than pre operative (mean $=30.5 ; \mathrm{SD}=6.74$ ) and it was statistically significant $(\mathrm{p}=0.001)$.

\section{Multivariate analysis}

Table 2 showed the results of a multiple linear regression. Table 2 showed that male had better post-operative knee society score than female and it was statistically significant $(b=5.90 ; p=0.015)$. Age had positive association on functional knee society score. Older patient who underwent total knee arthroplasty had better post-operative knee society score $(b=0.16 ; p=0.043)$.

Table 1. The results of $t$ test of knee society score between pre and post operative

\begin{tabular}{lccc}
\hline Knee society score & Mean & SD & p \\
\hline Pre operative & 30.5 & 6.74 & 0.001 \\
Post operative & 82.7 & 6.29 & \\
\hline
\end{tabular}

Table 2. The results of a multiple linear regression

\begin{tabular}{lcccc}
\hline Independent variables & b & SE & $\boldsymbol{\beta}$ & p \\
\hline Gender (female) & 5.90 & 3.14 & 0.36 & 0.015 \\
Age (year) & 0.16 & 0.25 & 0.15 & 0.043 \\
(Constant) & 75.03 & 17.52 & & $<0.001$ \\
b= unstandardized coefficient & & & & \\
$\beta=$ standardized coefficient & & & & \\
\hline
\end{tabular}

From the table 2, the $\mathrm{p}$ value 0,001 $(\mathrm{p}<0,050)$. This study shown that there is significant improvement of knee society score post-operatively in patient underwent 
Indonesian Journal of Medicine (2018), 3(3): 134-138

https://doi.org/10.26911/theijmed.2018.03.03.02

total knee arthroplasty using screw augmentation.

\section{DISCUSSION}

$\overline{\text { There are several options in management of }}$ bone deficiencies, especially proximal tibial defect in long-standing cases of osteoarthritis knee with varus deformity. Screw augmentation in total knee arthroplasty had been one of the option for treatment of osteoarthritis of the knee with tibial defect (Berend et al., 2014; Rajesh, 2012; Ritter \& Harty, 2004). From some studies, it shown no failure in knee that underwent total knee arthroplasty with screw augmentation in 7 years follow up (Canale, 2017).

In our study, our patient that fullfiled our criteria, evaluated using knee society score. It is shown that, in the January December 2016, 30 patient that had been selected, distributed as 25 females and 5 males, with average 54-73 years old. Knee society score post-operative in male patients shown better than the knee society score post-operative in female patients. Singh et al., (2008) reported that female had more moderate-severe pain after primary total knee arthroplasty compared to males in 2 years follow up.

Knee society score post-operative in older patients shown better compared with younger age. And this study support the studies by Ritter and Harty (2004) and Berend et al. (2014), which shown that there was significant improvement knee society score post-operatively, and no failure in 57 knees with defect of the tibia treated with total knee arthroplasty with screw augmentation.

\begin{tabular}{r}
\hline REFERENCES \\
\hline Abdeen AR, Collen SB, Vince KG (2010) \\
Fifteen-Year to 19-Year Follow-Up of
\end{tabular}

the Insall-Burstein-1 Total Knee Arthroplasty. Journal of Arthroplasty, 25(2), 173-178. https://doi.org/10.1016/j.arth.2009.01.009

Berend ME, Ritter MA, Keating EM, Jackson MD, Davis KE (2014). Use of screws and cement in primary TKA with up to 20 years follow-up. Journal of Arthroplasty, 29(6), 1207-1210. https://doi.org/10.1016/j.arth.2013.1 2.023

Bilgen MS, Eken G, Guney N (2017). Shortterm results of the management of severe bone defects in primary TKA with cement and K-wires. Acta Orthopaedica et Traumatologica Turcica, 51(5): 388-392. https://doi.org/10.1016/j.aott.2017.02.002.

Kouk S, Rathod PA, Maheshwari AV, Deshmukh AJ (2018). Rotating hinge prosthesis for complex revision total knee arthroplasty: A review of the literature. Journal of Clinical Orthopaedics and Trauma, 9(1): 29-33. https://doi.org/10.1016/j.jcot.2017.11. 020

Rajesh M (2012). Mastering orthopedic techniques - Hoffa Fracture. Mastering orthopedic techniques.

Ritter MA, Harty LD (2004). Medial screws and cement: A possible mechanical augmentation in total knee arthroplasty. Journal of Arthroplasty, 19(5), 587-589. https://doi.org/10.1016/j.arth.2003.11.009

Singh JA, Gabriel S, Lewallen D (2008). The impact of gender, age, and preoperative pain severity on pain after TKA. Clinical Orthopaedics and Related Research, 466(11), 27172723. https://doi.org/10.1007/s11999-008-0399-9 